\title{
Osseointegration of zirconia implants compared with titanium: an in vivo study
}

Rita Depprich ${ }^{1}$, Holger Zipprich², Michelle Ommerborn*3, Christian Naujoks $^{\dagger}{ }^{1}$, Hans-Peter Wiesmann ${ }^{4}$, Sirichai Kiattavorncharoen ${ }^{5}$, Hans-Christoph Lauer ${ }^{2}$, Ulrich Meyer ${ }^{1}$, Norbert R Kübler ${ }^{\dagger 1}$ and Jörg Handschel ${ }^{1}$

Address: ${ }^{1}$ Department of Cranio- and Maxillofacial Surgery, Heinrich-Heine-University, Düsseldorf, Germany, ${ }^{2}$ Department of Prosthetic Dentistry, Section of Materials Sciences, Johann Wolfgang Goethe University, Frankfurt, Germany, ${ }^{3}$ Department of Operative and Preventive Dentistry and Endodontics, Heinrich-Heine-University, Düsseldorf, Germany, ${ }^{4}$ Department of Cranio- and Maxillofacial Surgery, Westfalian Wilhelms-University, Münster, Germany and ${ }^{5}$ Department of Oral and Maxillo-Facial Surgery, Mahidol University, Bangkok, Thailand

Email: Rita Depprich - depprich@med.uni-duesseldorf.de; Holger Zipprich - zipprich@em.uni-frankfurt.de;

Michelle Ommerborn* - ommerborn@med.uni-duesseldorf.de; Christian Naujoks - christian.naujoks@med.uni-duesseldorf.de; Hans-

Peter Wiesmann - HansPeter.Wiesmann@ukmuenster.de; Sirichai Kiattavorncharoen - kiattav@hotmail.com; Hans-

Christoph Lauer - H.C.Lauer@em.uni-frankfurt.de; Ulrich Meyer - ulrich.meyer@med.uni-duesseldorf.de ;

Norbert R Kübler - kuebler@med.uni-duesseldorf.de; Jörg Handschel - handschel@med.uni-duesseldorf.de

* Corresponding author †Equal contributors

Published: II December 2008

Head \& Face Medicine 2008, 4:30 doi:10.1 186/1746-160X-4-30
Received: 8 July 2008

Accepted: II December 2008

This article is available from: http://www.head-face-med.com/content/4/I/30

(c) 2008 Depprich et al; licensee BioMed Central Ltd.

This is an Open Access article distributed under the terms of the Creative Commons Attribution License (http://creativecommons.org/licenses/by/2.0), which permits unrestricted use, distribution, and reproduction in any medium, provided the original work is properly cited.

\begin{abstract}
Background: Titanium and titanium alloys are widely used for fabrication of dental implants. Since the material composition and the surface topography of a biomaterial play a fundamental role in osseointegration, various chemical and physical surface modifications have been developed to improve osseous healing. Zirconia-based implants were introduced into dental implantology as an altenative to titanium implants. Zirconia seems to be a suitable implant material because of its tooth-like colour, its mechanical properties and its biocompatibility. As the osseointegration of zirconia implants has not been extensively investigated, the aim of this study was to compare the osseous healing of zirconia implants with titanium implants which have a roughened surface but otherwise similar implant geometries.
\end{abstract}

Methods: Forty-eight zirconia and titanium implants were introduced into the tibia of 12 minipigs. After I, 4 or 12 weeks, animals were sacrificed and specimens containing the implants were examined in terms of histological and ultrastructural techniques.

Results: Histological results showed direct bone contact on the zirconia and titanium surfaces. Bone implant contact as measured by histomorphometry was slightly better on titanium than on zirconia surfaces. However, a statistically significant difference between the two groups was not observed.

Conclusion: The results demonstrated that zirconia implants with modified surfaces result in an osseointegration which is comparable with that of titanium implants. 


\section{Background}

Since their introduction over 40 years ago, dental implants have become an established treatment modality that had revolutionized the concept of replacing missing teeth. The recent material of choice for manufacturing dental implants is commercially pure titanium, because of its excellent biocompatibilty and mechanical properties [1]. However, the gray colour of the titanium may be disadvantageous and give rise to esthetic problems, especially if the soft tissue situation is not optimal and the dark colour shines through the thin periimplant mucosa [2].

The success of endosseous implants is directly related to the principle of osseointegration, a process of implantbone interaction that finally leads to bone-to-implant anchorage [3]. As the surface topography of a biomaterial has a major impact on osseointegration, various chemical and physical surface modifications have been developed to improve osseous healing of implants. Increased surface roughness of dental implants resulted in greater bone apposition [4] and reduced healing time [5].

Zirconia ceramics (yttrium-stabilized tetragonal polycrystals) seem to be a suitable material for dental implants because of their tooth-like colour, their excellent mechanical properties and their good biocompatibility [6]. They have extensively been used as ball heads in total hip replacements with remarkable clinical outcomes [7]. Recent animal studies have also shown successful bone healing of dental zirconia implants under both unloaded and loaded conditions $[2,8-10]$. As the conventional fabrication of zirconia rods usually results in realtively smooth surfaces, only few studies have investigated rough surface modifications of zirconia implants. This is a critical aspect, since it has been already demonstrated that surface roughness and topography also influence osseointegration of zirconia implants [6,11-13].

In comparison with titanium implants, much less is known about the role played by surface modifications on the osseointegration of zirconia implants. Thus, the aim of the present study was to examine the osseous healing of zirconia implants with acid-etched surface structures in comparison with titanium implants.

\section{Methods}

\section{Experimental animals}

Twelve minipigs ( $>5$ years, average body weight $66.5 \mathrm{~kg}$ ) were used in this study. The investigation was approved by the Animal Ethics Committee at the University of Düsseldorf, Germany. The animals were kept in small groups in purpose-designed sties and fed on a standard diet. Twelve hours before surgery animals were denied feed although water was accessible ad libitum.

\section{Implant system}

Twenty-four screw-type zirconia implants (yttrium-stabilized tetragonal poly-crystals) with modified (acidetched) surfaces ( $\mathrm{Ra}=0.598 \mu \mathrm{m}$, according to manufacturer) were used and compared to twenty-four implants made of commercially pure titanium with acid-etched surfaces $(\mathrm{Ra}=1.77 \mu \mathrm{m}$, according to manufacturer). Implants were supplied by Konus Dental Implants (Bingen, Germany). All implants had the same macroscopic design with a standardized diameter of $3.5 \mathrm{~mm}$ and a length of $9 \mathrm{~mm}$.

\section{Surgical procedure}

All surgeries were performed under sterile conditions in a veterinary operating theatre. The animals were sedated by an intramuscular injection $(10 \mathrm{mg} / \mathrm{kg}$ ) of ketamine (Ketavet $^{\oplus}$, Pfizer, Karlsruhe, Germany), $1 \mathrm{ml}$ atropine (Atropinsulfat Braun ${ }^{\circledast}$, Braun, Melsungen, Germany) and $5 \mathrm{mg} /$ kg azaperone (Stresnil ${ }^{\circledR}$, Janssen-Cilag, Neuss, Germany).

Anesthesia was induced with an intravenous bolus of 3-5 $\mathrm{ml}$ thiopental (Thiopental inresa ${ }^{\circledR}$, Inresa Arzneimittel, Freiburg, Germany) followed by intubation and maintenance of anaesthesia by inhalation of $1.5 \%$ isoflurane. For analgesia animals received $0.5 \mathrm{ml}$ piritramide (Dipidolor ${ }^{\oplus}$, Janssen-Cilag, Neuss, Germany). In the areas to be exposed to surgery, $5 \mathrm{ml}$ of local anaesthesia [articain hydrochloride, (Ultracain ${ }^{\circledast}$ DS, 1:200.000), Aventis, Frankfurt, Germany] was injected. The tibias were exposed by skin incisions and via fascial-periosteal flaps. Thereafter, four implants were placed in the tibia. The implant sites were sequentially enlarged with two drills according to the standard protocol of the manufacturer. Implants measuring $9 \mathrm{~mm}$ in length and $3.5 \mathrm{~mm}$ in diameter were inserted using continuous external sterile saline irrigation to minimize bone damage caused by overheating. At the surgical site, the skin and the fascia-periosteum were closed in separate layers with single resorbable sutures (Vicryl ${ }^{\circledR} 2-0$, Ethicon, Norderstedt, Germany). Perioperatively, the animals received amoxicillin $(10 \mathrm{mg} / \mathrm{kg} \mathrm{KG})$ (Duphamox LA ${ }^{\oplus}$, Fort Dodge, Würselen, Germany) as antibiotic and carprofen p.o. (4.4 mg/kg) (Rimadyl ${ }^{\circledR}$, Pfizer, Karlsruhe, Germany) as antiphlogistic medication for three days. The animals were inspected after the first few postoperative days for signs of wound dehiscence or infection and, thereafter, weekly to assess general health. After 1, 4 or 12 weeks animals were sacrificed (4 minipigs each) with an overdose of pentobarbital (Eutha $77^{\circledR}$, Essex Pharma, München, Germany) given intravenously. Following euthanasia, tibia block specimens containing the implants and surrounding tissues were dissected from the animals. The block samples were sectioned with a saw to remove unnecessary fragments of bone and soft tissue and were prepared for the subsequent investigations. 


\section{Histological analyses}

The implants were immediately fixed in $4 \%$ buffered formaldehyde for approximately one week. Then the specimens were dehydrated in a graded series of ethanol. Thereafter, samples were embedded in methyl metacrylate (Technovit ${ }^{\circledR} 7200$, Heraeus Kulzer, Dormagen, Germany). With the help of the cutting-grinding technique according to Donath, longitudinal sections were ground to about 20-40 $\mu \mathrm{m}$ for conventional microscopy (Exakt Apparatebau, Norderstedt, Germany). Two central histological sections of each implant were obtained and samples were stained with toluidine blue and Masson-Trichrome-Goldner. The slides were examined and photographed with a Leica DM 5000B (Leica Microsystems, Wetzlar, Germany) light microscope, equipped with a Leica DC 300F high resolution camera.

\section{Histomorphometry}

Histomorphometric evaluation was performed after one central slice was chosen at 50-fold magnification using a digital camera. The software ImageJ $1.37 \mathrm{v}^{\circledast}$ (open source: http://rsb.info.nih.gov/ij/features.html) was used to measure the bone-to-implant contact (BIC) ratio, defined as the length of bone surface border in direct contact with the implant $(\times 100(\%))$.

\section{Statistical analysis}

All calculations were performed with the help of SPSS for Windows (SPSS Inc., Chicago, IL, USA). The results from the histomorphometric measurements were expressed as means \pm standard deviations. The different treatment groups were compared using a Mann-Whitney $U$ test. A p $<0.05$ was set for significance.

\section{Results}

The animals recovered well after surgery and no signs of infection were noted upon clinical examination at any time during the observation period (Figure 1). Light microscopical analysis demonstrated that matrix-rich regeneration tissue displaced the blood clot between the implant surface and the bone tissue in the first week after surgical procedure (Figure 2). After 4 weeks, mature regeneration tissue with formation of osteoid and woven bone was observed (Figure 3). Close contact of the bone to the implant was seen both on titanium and zirconia surfaces. Circumferential bone tissue formation was detectable on the zirconia implant surface. After 12 weeks of healing, hard tissue integration of the titanium as well as the zirconia implants was achieved. Mature lamellar bone in direct contact to the titanium and zirconia implants was found (Figure 4). No signs of inflammation were detected in any of the specimens. Histologically detectable minor differences between the zirconia and the titanium implants were no longer evident.

The bone-to-implant contact increased over the examination period for both zirconia and titanium implants (Figure 5). After 1 week of healing, the mean BIC was $35.3 \%$ \pm 10.8 for the zirconia and $47.7 \% \pm 9.1$ for the titanium implants, respectively. After 4 weeks in situ, BIC of the zirconia implants averaged $45.3 \% \pm 15.7$ and $58.6 \% \pm 9.5$ for the titanium implants. After 12 weeks the BIC values

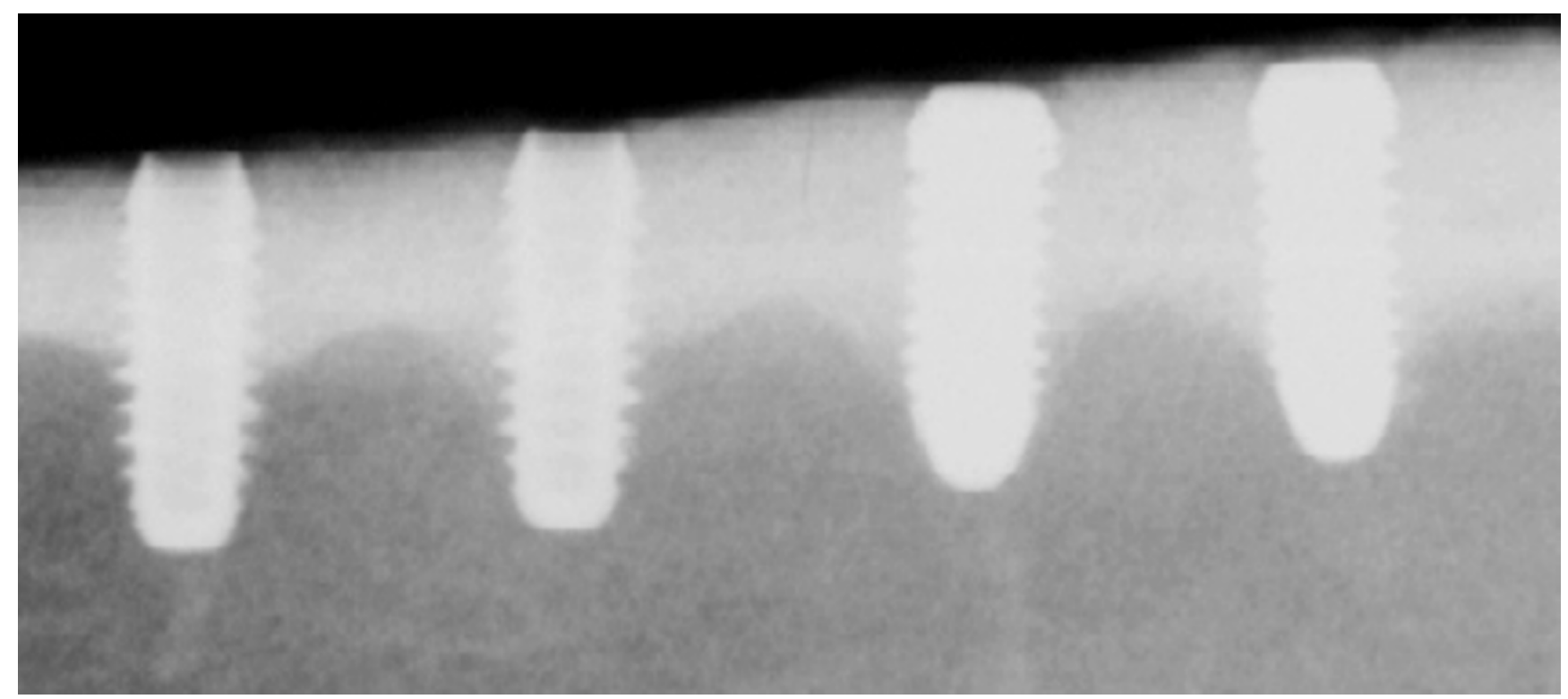

\section{Figure I}

Radiograph showing titanium (left) and zirconia (right) implants inserted into the tibia of minipigs after 12 weeks of healing time. 

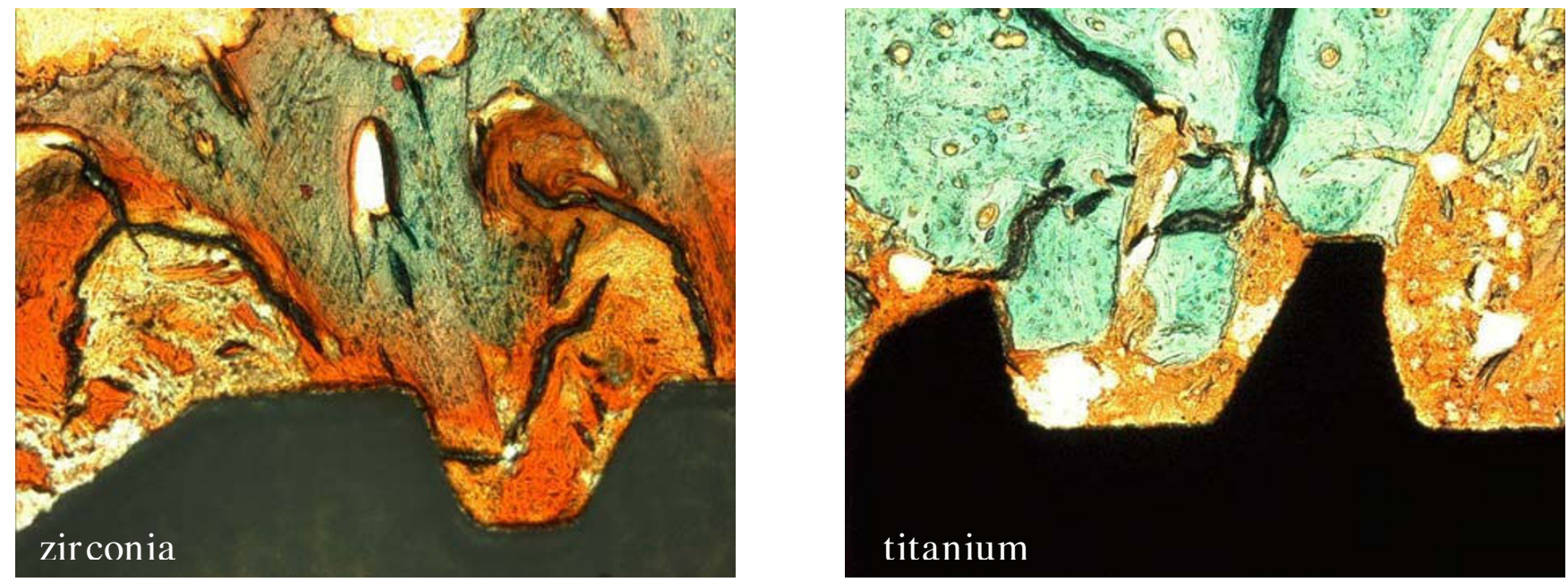

Figure 2

Micrograph showing matrix-rich regeneration tissue (orange) between the implant and bone (green). Zirconia implant (left), titanium implant (right) (Masson-Trichrome-Goldner, I00-fold).

were $71.4 \% \pm 17.8$ for the zirconia implants and $82.9 \% \pm$ 10.7 for the titanium implants. There were no statistically significant differences observed betweeen the titanium and zirconia implants $(\mathrm{p}<0.05)$ in regards to bone-toimplant contact after 1,4 or 12 weeks.

\section{Discussion}

Zirconia is a bioinert nonresorbable metal oxide that offers mechanical properties which are superior over other ceramic biomaterials, e.g. high fracture toughness and bending strength [14]. Because of its good chemical and material stability, high strength and resilience it seems to be a suitable material for dental application [7]. Its suc-

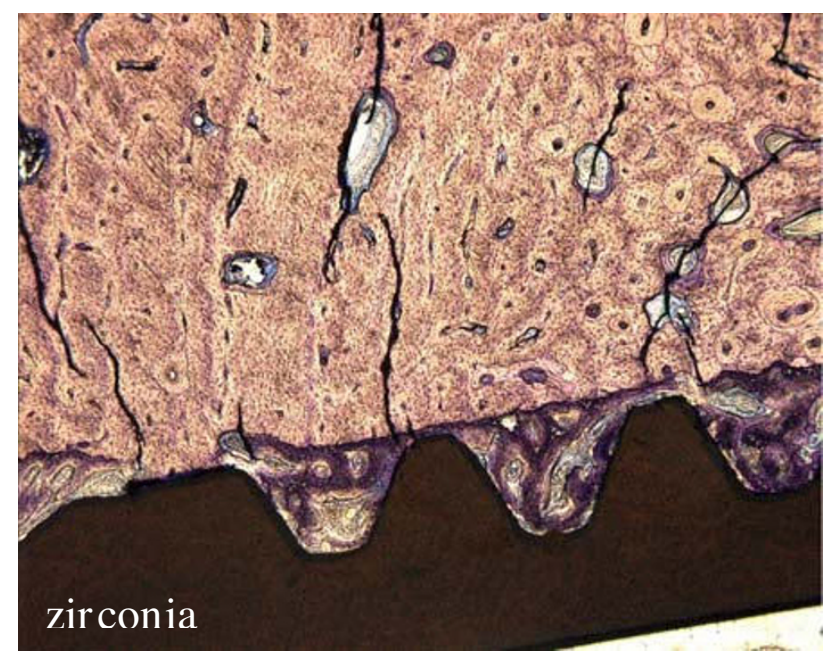

cessful application in dentistry for fabricating endodontic posts and for crown and bridge restorations has been reported in several studies [15-17]. Especially because of its tooth-like colour, zirconia was suggested to be a desirable alternative material to titanium for the fabrication of dental implants. The results of the present study have shown that zirconia implants fabricated with a modified surface seem to be integrated into bone in a similar fashion as titanium.

After one week of healing, distinct gaps between the implant and the bone filled with matrix-rich regeneration tissue were observed in a few locations. After 4 weeks,

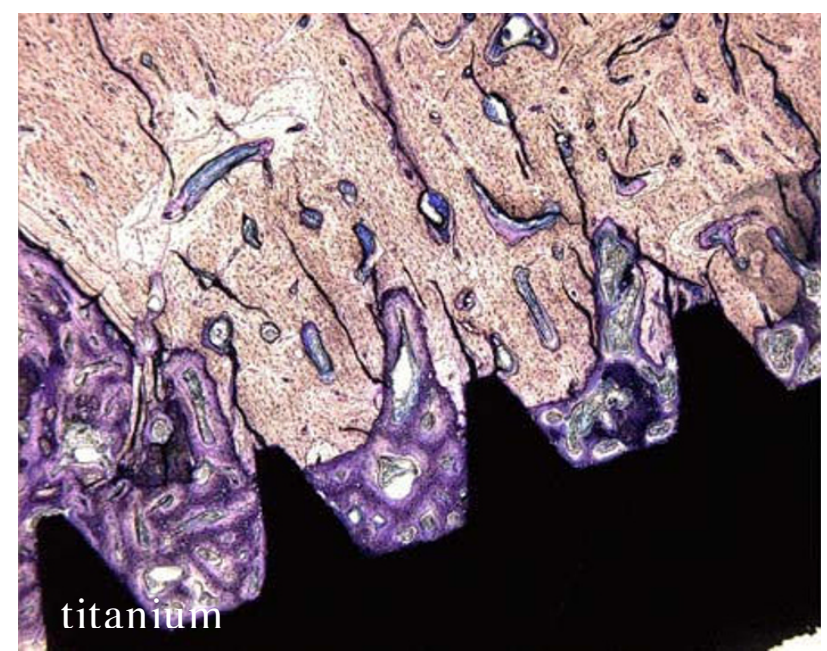

\section{Figure 3}

At 4 weeks after implantation, osteoid and woven bone were formed both on zirconia (left) and titanium implant surfaces (right) (toluidine blue, $\mathbf{5 0}$-fold). 

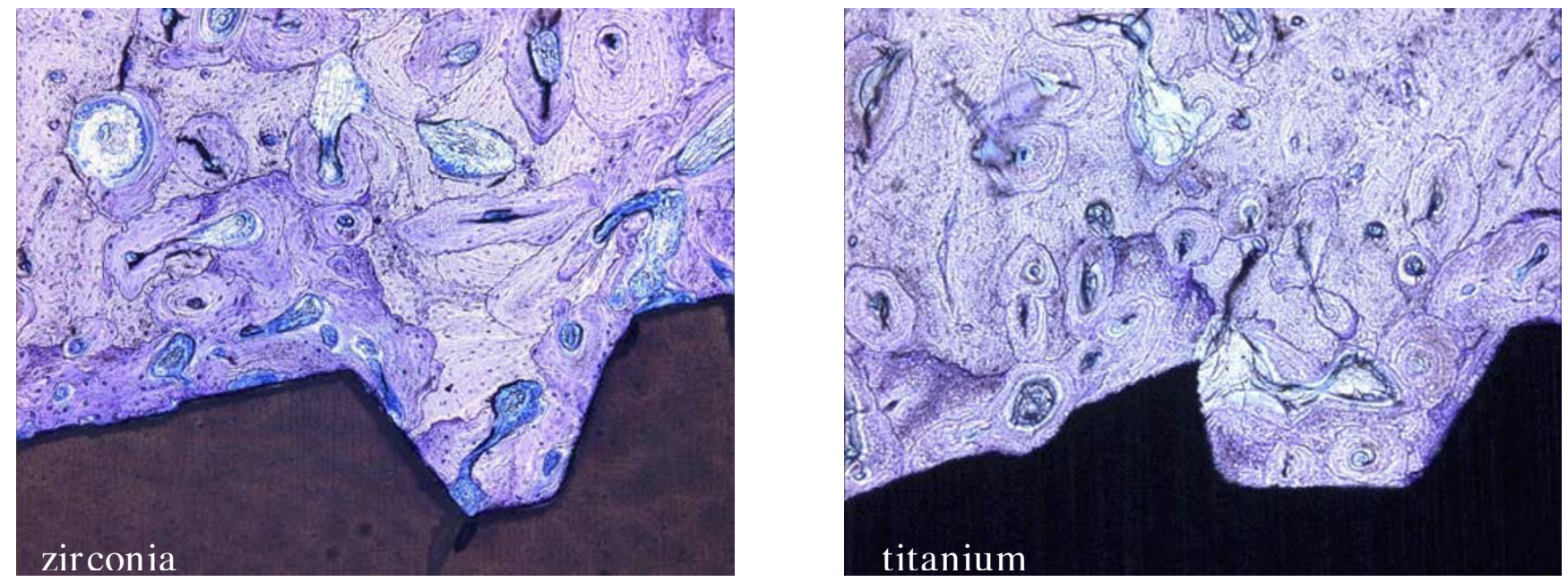

Figure 4

After 12 weeks of healing, mature lamellar bone is evident in intimate contact with the zirconia implant (left) and titanium implant (right) (toluidine blue, I00-fold).

woven bone, and after 12 weeks, lamellar bone, was visible in intimate contact with the implant surfaces. A loose connective tissue layer separating bone tissue and the zirconia surface as described by Sennerby et al. [6] previously, was not found in our samples.

Osseointegration of threaded zirconia implants has been recently investigated by Rothamel et al. [18]. They compared the osseous healing of zirconia implants with modified (machined and sand blasted) implant surfaces from polished commercially pure titanium. After 4 days of healing time, a distinct gap between bone tissue and the implant surface filled with remodelling blood clot was noticed. Two weeks after implantation, woven bone growing in the direction of the implant was observed, followed by the formation of lamellar bone after 28 days. When the healing period was nearly completed after 8 weeks, intimate contact of lamellar bone to the implant surface was evident. However, the barrier resulting from the original gap was still visible with many osteoblasts bridging the gap, which indicates a high biocompatibility of the used implant materials.

The results of the present study also showed an increasing BIC over the healing period. However, there were no statistically significant histomorphometrical differences observed between zirconia and titanium implants. This finding is in accordance with other animal studies which also failed to demonstrate differences between structured zirconia and titanium implant surfaces $[2,6,8,12,19]$, likely secondary to the fact that zirconia is highly biocompatible. An average BIC $>60 \%$, which was achieved after 4 weeks following implantation, had been reported by several authors $[2,6,10,18]$. The reported differences in BIC seem to be attributable to different animal models (dogs, monkeys, rabbits and minipigs) used for the experiments $[2,9,20]$. In order to establish standardized conditions for the histomorphometric analysis, implants were placed in the tibia since this bone has constant bone geometries over a longer distance. Therefore, the BIC only depends on the implant osseointegration and not on the bone features at the implantation site. In contrast to the results from a similar study [21], there were no detachment or separation of bone tissue and the zirconia surface with loose connective tissue detectable at any time.

The BIC measured in our study (45.3\% after 4 weeks) showed similar results as demonstrated by Sennerby et al. [6]. The authors demonstrated a BIC of 36\% for the nonmodified zirconia implants and BICs of more than $45 \%$ for the zirconia implants with surface modification after 6 weeks of healing in the tibia of rabbits.

Scarano et al. [10] observed $68 \%$ BIC of the untreated zirconia implants after 4 weeks in the tibia of rabbits. After 6 months of unloaded healing in the mandibles of dogs, Dubruille et al. [9] measured a BIC of $65 \%$ for the zirconia implants compared with $68 \%$ of alumina implants and $54 \%$ of the titanium implants. The surface topography of the implants in these studies was not investigated. Kohal and coworkers [2] determined slightly higher BIC values after implant insertion into the maxillae of monkeys followed by 5 months of loaded healing (68\% for sandblasted zirconia implants and $73 \%$ for sandblasted and acid-etched titanium implants). However, the surface topography was not measured or described. In the present 


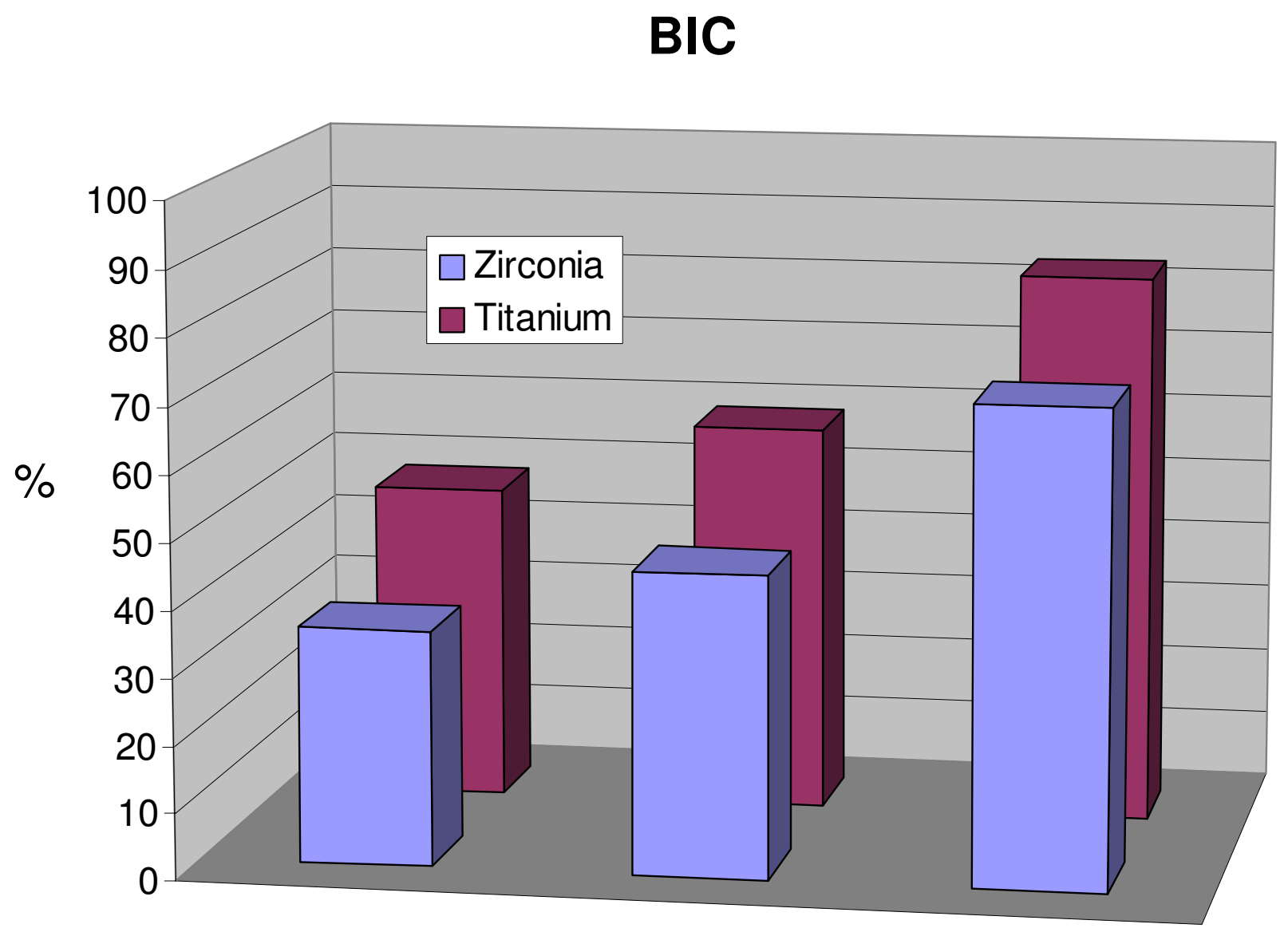

1 week $\quad 4$ weeks 12 weeks

\section{Figure 5}

Diagram depicting the increase in bone-to-implant contact (BIC) with time (I, 4, I 2 weeks). No statistical significance was detected between the two treatment groups $(p<0.05)$.

study, a BIC of $71 \%$ for the acid-etched zirconia and $83 \%$ for acid-etched titanium implants were measured after 3 months of implant insertion.

It is well known that surface modifications can enhance bone integration of titanium implants in diverse animal models $[22,23]$. According to the results of several earlier experimental studies, surface roughness and topography influence osseointegration of zirconia implants to a greater extend [11-13]. Sennerby et al. [6] used a coating technique to receive porous surface modifications of the zirconia implants (nonmodified implants: $\mathrm{Sa}=0.75 \mu \mathrm{m}$; modified implants: $\mathrm{Sa}=0.93 \mu \mathrm{m}$, $\mathrm{Sa}=1.24 \mu \mathrm{m}$, respectively). In spite of evident differences in surface roughness, there were no significant differences observed in the osseointegration (BIC or bone area filling in the threads) in the investigated implants. Only removal torque test val- ues were significantly lower of the nonmodified zirconia implants compared with all other implant types. These results and the results of Scarano et al. [10], who used unmodified zirconia implants, indicate a considerable biocompatibility of zirconia implants, even without surface treatment.

In contrast to the study of Sennerby et al. [6], an acid-etching technique was used in this study to receive structured surface modification of zirconia implants. Surface modification by acid-etching is assumed to affect not only the microtopography, but also submicrometric and nanometric topography of implant materials. Sa or Ra values only refer to the average surface roughness. These values do not provide much information about the submicrometric and nanometric surface topography ( $\mathrm{Ra}$ is the two-dimensional (2D) counterpart of the three-dimensional (3D) 
descriptor Sa. Both Ra and Sa reflect the arithmetic mean of the absolute values of the surface point departures from the mean plane within the sampling area [24]).

Submicrometric and nanometric topography determine cell reactions including cell orientation, changes in cell motility, cell adhesion and cell shape. Therefore these topographic features play an important role in the early state of osseointegration of dental implants [25]. In addition, differences in the physico-chemical properties of the material also affect cell responses [26].

The successful integration of zirconia implants into native bone tissue and comparable BIC was demonstrated in this study, however the used modified zirconia implants exhibited a considerable lower Ra value when compared to the titanium implants. Furthermore, the process of osseointegration of zirconia implants showed similarities to that known for titanium implants. This may be due to the fact that surface topography is not the only controlling factor when studying the biologic response to an implant material.

The results of earlier described studies implicate a good biocompatibilty even of unmodified zirconia implants. The submicrometric and nanometric topography of the zirconia surfaces produced by the acid-etched modification may have an additional synergistic effect on biocompatibilty and osseointegration of zirconia implants [27]. Further studies are needed to examine the influence of submicrometric and nanometric surface topography of zirconia implants to the osseointegration process.

\section{Conclusion}

The results from our study suggest that zirconia implants with modified surfaces display features of osseointegration similar to those of titanium implants. These results are promising in using zirconia implants for dental application in the future.

\section{Competing interests}

The authors declare that they have no competing interests.

\section{Authors' contributions}

$\mathrm{UM}, \mathrm{CN}, \mathrm{JH}$ conceived the study design and performed surgery. HPW carried out the histological analysis and drafted the manuscript. RD participated in the design of the study, performed surgery and wrote the manuscript. $\mathrm{HZ}, \mathrm{MO}, \mathrm{SK}, \mathrm{HCL}$, NRK participated in the early preparation of the manuscript and contributed to write the revised version of the article. All authors read and approved the final manuscript.

\section{Acknowledgements}

The authors thank Dr. M. Sager and Ms. I. Schrey for their help and commitment to the realization of the animal study. The authours also kindly appreciate the skills and commitment of C. Willamoski, S. Haumann, I. Nowak to the preparation of the histological specimens. This study was supported by the University of Düsseldorf, Germany. The implants were donated by Konus Dental Implants (Bingen, Germany).

\section{References}

I. Smith DC: Dental implants: materials and design considerations. Int J Prosthodont 1993, 6:106-17.

2. Kohal RJ, Weng D, Bachle M, Strub JR: Loaded custom-made zirconia and titanium implants show similar osseointegration: an animal experiment. J Periodontol 2004, 75: I 262-8.

3. Triplett RG, Frohberg U, Sykaras N, Woody RD: Implant materials, design, and surface topographies: their influence on osseointegration of dental implants. J Long Term Eff Med Implants 2003, I 3:485-50I.

4. Buser D, Broggini N, Wieland M, Schenk RK, Denzer AJ, Cochran DL, Hoffmann B, Lussi A, Steinemann SG: Enhanced bone apposition to a chemically modified SLA titanium surface. IJ Dent Res 2004, 83:529-33.

5. Cochran DL, Buser D, ten Bruggenkate CM, Weingart D, Taylor TM, Bernard JP, Peters F, Simpson JP: The use of reduced healing times on ITI implants with a sandblasted and acid-etched (SLA) surface: early results from clinical trials on ITI SLA implants. Clin Oral Implants Res 2002, I 3: I44-53.

6. Sennerby L, Dasmah A, Larsson B, lverhed M: Bone tissue responses to surface-modified zirconia implants: $A$ histomorphometric and removal torque study in the rabbit. Clin Implant Dent Relat Res 2005, 7(SuppI I):SI 3-20.

7. Piconi C, Maccauro G, Muratori F, Brach del Prever E: Alumina and zirconia ceramics in joint replacements. Journal of Applied Biomaterials \& Biomechanics 2003, I:19-32.

8. Akagawa Y, Hosokawa R, Sato Y, Kamayama K: Comparison between freestanding and tooth-connected partially stabilized zirconia implants after two years' function in monkeys: a clinical and histologic study. J Prosthet Dent 1998, 80:55 I-8.

9. Dubruille JH, Viguier E, Le Naour G, Dubruille MT, Auriol M, Le Charpentier $Y$ : Evaluation of combinations of titanium, zirconia, and alumina implants with 2 bone fillers in the dog. Int J Oral Maxillofac Implants 1999, 14:27|-7.

10. Scarano A, Di Carlo F, Quaranta M, Piattelli A: Bone response to zirconia ceramic implants: an experimental study in rabbits. J Oral Implantol 2003, 29:8-I2.

II. Bachle M, Butz F, Hubner U, Bakalinis E, Kohal RJ: Behavior of CAL72 osteoblast-like cells cultured on zirconia ceramics with different surface topographies. Clin Oral Implants Res 2007, I 8:53-9.

12. Gahlert M, Gudehus T, Eichhorn S, Steinhauser E, Kniha H, Erhardt $W$ : Biomechanical and histomorphometric comparison between zirconia implants with varying surface textures and a titanium implant in the maxilla of miniature pigs. Clin Oral Implants Res 2007, 18:662-8.

13. Li J, Fartash B, Hammarström L, Hermansson L: Effect of macrotexture produced by laser beam machining on the retention of ceramics implant in bone in vivo. Mater in Medicine 1994, 5:760-763.

14. Piconi C, Maccauro G: Zirconia as a ceramic biomaterial. Biomaterials 1999, 20: I-25.

15. Ahmad I: Restitution of maxillary anterior aesthetics with allceramic components. Int Dent J 2002, 52:47-56.

16. Meyenberg $\mathrm{KH}$, Luthy $\mathrm{H}$, Scharer P: Zirconia posts: a new allceramic concept for nonvital abutment teeth. J Esthet Dent 1995, 7:73-80.

17. Sturzenegger B, Feher A, Luthy H, Schumacher M, Loeffel O, Filser F, Kocher P, Gauckler L, Scharer P: [Clinical study of zirconium oxide bridges in the posterior segments fabricated with the DCM system]. Schweiz Monatsschr Zahnmed 2000, I I 0:131-9.

18. Rothamel D, Ferrari D, Herten M, Schwarz F, Becker J: Biokompatibilität und Hartgewebsintegration einphasiger oberflächenstrukturierter Zirkoniumoxidimplantate-Eine kombinierte in-vitro- und in-vivo-Studie. Implantologie 2007, I 5:405-4I4.

19. Akagawa Y, Ichikawa Y, Nikai H, Tsuru H: Interface histology of unloaded and early loaded partially stabilized zirconia endosseous implant in initial bone healing. J Prosthet Dent 1993, 69:599-604. 
20. Wenz HJ, Bartsch J, Wolfart S, Kern M: Osseointegration and clinical success of zirconia dental implants: a systematic review. Int J Prosthodont 2008, 21:27-36.

21. Chang YS, Oka M, Nakamura T, Gu HO: Bone remodeling around implanted ceramics. J Biomed Mater Res 1996, 30:1 17-24.

22. Gotfredsen $\mathrm{K}$, Berglundh $\mathrm{T}$, Lindhe J: Anchorage of titanium implants with different surface characteristics: an experimental study in rabbits. Clin Implant Dent Relat Res 2000, 2: I20-8.

23. Albrektsson $T$, Johansson C: Osteoinduction, osteoconduction and osseointegration. Eur Spine J 200I, I0(Suppl 2):S96-I0I.

24. Shalabi MM, Gortemaker A, Van't Hof MA, Jansen JA, Creugers NH: Implant surface roughness and bone healing: a systematic review. J Dent Res 2006, 85:496-500.

25. Meyer U, Buchter A, Wiesmann HP, Joos U, Jones DB: Basic reactions of osteoblasts on structured material surfaces. Eur Cell Mater 2005, 9:39-49.

26. Schwartz Z, Kieswetter K, Dean DD, Boyan BD: Underlying mechanisms at the bone-surface interface during regeneration. J Periodontal Res 1997, 32:166-71.

27. Morra M, Cassinelli C, Bruzzone G, Carpi A, Di Santi G, Giardino R, Fini M: Surface chemistry effects of topographic modification of titanium dental implant surfaces: 1 . Surface analysis. Int J Oral Maxillofac Implants 2003, 18:40-5.

Publish with Bio Med Central and every scientist can read your work free of charge

"BioMed Central will be the most significant development for disseminating the results of biomedical research in our lifetime. "

Sir Paul Nurse, Cancer Research UK

Your research papers will be:

- available free of charge to the entire biomedical community

- peer reviewed and published immediately upon acceptance

- cited in PubMed and archived on PubMed Central

- yours - you keep the copyright

Submit your manuscript here:

http://www.biomedcentral.com/info/publishing_adv.asp
BiolMedcentral 